\title{
VIDAS VULNERÁVEIS: SER MIGRANTE EM TEMPOS DE CONSERVADORISMO E CRISE PANDEMICA NA AMÉRICA LATINA.
}

\author{
Gustavo DIAS ${ }^{1}$ \\ Fulvio Rivero SIERRA ${ }^{2}$
}

\begin{abstract}
Nunca ninguém contou essas pessoas e ninguém, inclusive as organizaçóes de assistência da ONU, jamais as contará: são milhôes, escapam à contagem e constituem o que é chamado - por falta de termo melhor ou de um maior grau de compaixão - de migração (BRODSKY, 2018, p.16).
\end{abstract}

A América Latina, bem como outros espaços geopolíticos, tem experimentado, um brusco giro conservador na última década. Em diferentes escalas, governos de direita e de extrema-direita, atrelados às lideranças religiosas, políticas e intelectuais conservadoras, substituíram governos de centro e centro-esquerda. Junto com essa recente onda, presenciamos também, após um breve intervalo de ordem progressista, o ressurgimento da agenda neoliberal, que atuou fortemente, logo após o fim dos regimes ditatoriais na região, e adentrou a década de 1990. Nesse cenário político e econômico, assistimos, ainda, o brotar, com maior protagonismo, de um forte discurso nacionalista conservador. Por meio de práticas radicais, exaltam o ciclo das ditaduras militares, a restrição das liberdades de expressão e organização e combatem o reconhecimento político de minorias

1 Universidade Estadual de Montes Claros, Montes Claros - MG - Brasil. Professor permanente do Programa de Pós-Graduação em Sociedade, Ambiente e Território (PPGSAT - UFMG/Unimontes) e do Departamento de Ciências Sociais. https://orcid.org/0000-0001-5325-3253.tentonidias@hotmail.com.

2 Universidade Nacional de Tucumán-CONICET, San Miguel de Tucumán - Tucumán - Argentina. Professor Adjunto encarregado de "Metodologia de Pesquisa Científica" e "Técnicas de Pesquisa", no curso de Ciências da Comunicação. https://orcid.org/0000-0002-8538-0350. fulviorivero@conicet.gov.ar. 
sociais, bem como a presença de migrantes em suas mais distintas classificaçôes jurídicas. Acompanhamos, através de estudos e manchetes, populaçóes migratórias sendo indiscriminadamente responsabilizadas pelas inseguranças sociais e econômicas vividas nos territórios nacionais e, sobretudo, em zonas de fronteira. Em diversos países, foram registradas formas de xenofobia social e estatal sofridas por certas categorias de migrantes. Os exemplos, como serão apresentados ao longo deste dossiê, são inúmeros ${ }^{3}$. Medo, insegurança, confusão, exclusão e precariedade são exacerbados na existência desses migrantes. Soma-se a isso o espalhamento da COVID-19 por toda a regiáo e o duro impacto que ela trouxe para as zonas de fronteira. Um dos principais usos políticos da pandemia tem sido o de aprofundar um intenso sentimento de suspeita do estrangeiro como aquele responsável por trazer o vírus e, por conseguinte, a morte. Em tempos de pandemia, a suspeita exacerba-se como também o medo de que esses corpos alheios sejam vetores de contágio. Variadas fobias, durante a pandemia, impactam de diferentes maneiras a população em condição de mobilidade humana nas Américas. ${ }^{4}$

Diante desse giro conservador e, agora, potencializado pelo espalhamento da pandemia ao longo da América Latina, argumentamos aqui que pouco se sabe acerca da experiência vivida por esses sujeitos migrantes a partir de sua própria experiência cotidiana. Pesquisas, em geral, tendem a focar questóes migratórias num âmbito macro de análise. Apesar de sua relevância, o estudo de leis e políticas migratórias, bem como de controles fronteiriços tornam-se, em diversos casos, excessivamente concebidas dentro de uma tradição de pensar migraçóes através da lógica do próprio Estado. Em outras palavras, corremos o risco de seguir analisando o migrante enquanto um problema social e a migração enquanto geradora de "crises" (SAYAD, 2010).

Ao abordarmos exclusivamente essa dimensão, formas de resistências, saberes práticos e habilidades produzidos por esses sujeitos migrantes, para assegurar suas existências em tal cenário, passam despercebidas. Sabemos que a interação com fronteiras é uma característica inescapável para muitos migrantes. É um modo de estar no mundo (BENEDETTI, 2014; RIVERO SIERRA, 2018).

\footnotetext{
3 A ordem dos artigos que criamos nesse dossiê buscou atender o diálogo com esse texto de abertura. Portanto, trata-se de uma ordem aleatória e que pode ser rearranjada de formas distintas.

4 Para maiores informações, indicamos consultar o projeto (In)movilidad en las Américas. Covid-19 (https:// www.inmovilidadamericas.org/). Trata-se de um projeto em constante construção, que reflete coletivamente na (I) mobilidade das Américas durante a pandemia. Propõe, portanto, mapear as respostas do estado; as situações de alerta enfrentadas pela população migrante, em particular deslocados internos, deportados, detidos, requerentes de asilo, refugiados, migrantes irregulares, adultos ou crianças e adolescentes; e respostas sociais em cada um dos dois espaços nacionais.
} 
Mas, como eles vivenciam o cotidiano em cenário tão normativo? Como lidam diariamente com a xenofobia? De que forma circulam pelo tecido urbano? Conseguem moradia, acesso a saúde ou educação? Em sociedades como a peruana, brasileira e a argentina onde o desemprego e o trabalho informal atingem números expressivos, como esses sujeitos migrantes asseguram uma vida material e social digna?

Em vista disso, esse dossiê contribui para o campo dos estudos migratórios, nas ciências sociais, ao demonstrar que não podemos compreender o migrante e sua existência vulnerável sem questionar o "estatuto social e científico" dado pelo Estado ou pela academia a esse sujeito. $\mathrm{O}$ estudo da migraçáo é por excelência o estudo do pequeno. Pequeno não no sentido de importância, mas de uma "sociologia dos objetos situados relativamente na parte inferior da hierarquia social dos objetos de estudo, ou 'pequena' sociologia" (SAYAD, 1998, p. 22). Pequeno enquanto marginal. Trata-se de um sujeito que chega com prazo de validade. Uma identidade temporária destituída, em muitos casos, de cidadania, mas que tem uma função social clara para a sociedade receptora: trabalhar, enquanto houver trabalho. Provisoriedade e um passado apagado o insere num lugar social bastardo, na fronteira entre o ser e o não ser social. Argumentamos sobre a necessidade do pesquisador, enquanto um artesáo intelectual, valendo-se do conceito de Wright Mills (1959), ajuste as suas interrogaçóes, seus conceitos, seus instrumentos de pesquisa e seus preceitos a esse objeto e suas particularidades. Assim, o pesquisador precisa buscar caminhos alternativos para superar esse olhar do estado. A arte de encontrar o narrador e ouvi-lo ganha suma importância. Abdelmalek Sayad (1985) ressalta a importância de o pesquisador conhecer o limite do seu discurso, o discurso do acadêmico. Este, imbuído de autoridade científica, não pode cair no erro de obscurecer o discurso autêntico do informante, aquele que produz a teoria da migração.

\section{A América Latina entre giros progressistas e conservadores}

Entre os finais da década de 1990 e de 2000, grande parte da América Latina, de forma geral, testemunhou profundas transformaçóes no cenário político. Foi um rápido, mas marcante, período progressista em que a região experimentou a ascensão de governos de centro-esquerda e esquerdas que, apesar de suas disparidades e contradiçóes, foram caracterizados por políticas sociais que destinaram maior atenção às populaçóes historicamente marginalizadas na região (FÉLIZ; PINASSI, 2017). Tais foram os casos dos governos da Venezuela, Argentina, Brasil, Equador, Bolívia, Honduras, Paraguai e Uruguai. Esse fenô- 
meno constituiu um bloco regional que, ao menos, compartilhava de uma visáo contrária às formas de governos neoliberais que dominaram a cena política de meados da década de 1980 até então. Em geral, eram governos que assumiram a obrigação de superar as históricas desigualdades regionais, fruto de um longo estamento burocrático, que ganhou contornos mais agudos com o projeto hegemônico do neoliberalismo imposto a partir do Consenso de Washington, no início da década de 1990. Em decorrência disso, as transformaçóes apareceram em ritmo e intensidade diferentes. Governos como, por exemplo, os de Evo Morales e Rafael Correa propuseram constituiçóes bastante arrojadas e inclusivas. Todavia, em outros países, como Brasil e Argentina, registrou-se a ascensão eleitoral de forças políticas que se apresentaram como antineoliberais, mas que, contudo, não produziram rupturas drásticas nem dramáticas no sistema político, no mercado financeiro ou no domínio de elites nacionais (ZIBECHI; MACHADO, 2017; RODRIGUES, 2009; FÉLIZ; PINASSI, 2017).

Em suma, não se tratou de uma ruptura profunda. Presenciamos, não obstante, consideráveis taxas de crescimento econômico regional e inédita redução da pobreza e da extrema pobreza regional, por meio de uma pauta econômica centrada e na exportação de minério, petróleo e proteína vegetal e animal com o intuito de atender a alta demanda chinesa. No caso de países como o Brasil e a Argentina, por exemplo, houve uma trágica intensificação de longos processo de desindustrialização vividos por esses dois países e, por conseguinte, a reprimarização de suas respectivas economias (KATZ, 2016; PINASSI, 2017). Por outro lado, presenciamos também, por parte desses governos, um maior aceite e busca pela integração regional. Destacam-se aqui a proposta de intensificar blocos econômicos e acordos regionais com o claro intuito de superar, o que José Briceño-Ruiz (2020), por exemplo, bem define como o ciclo pós-liberal ou pós-hegemônico. Claro, algumas políticas regionais não sofreram grandes mudanças. Todavia,

[...]novas iniciativas surgiram, como a Alternativa Bolivariana para as Américas (ALBA), [...] mais tarde seria chamada Aliança Bolivariana para os Povos da América. Em 2008, foi criada a União de Naçôes SulAmericanas (UNASUL), esquema regional que deu continuidade a iniciativas brasileiras como a Área de Livre Comércio da Sul-Americana (ALCSA) (1994) e a Comunidade Sul-Americana de Naçóes (CASA) (2000). Igualmente, em dezembro de 2011 foi criada a Comunidade de Estados da América Latina e do Caribe (CELAC), iniciativa resultante da 
ação de Felipe Calderón e Luiz Inácio Lula da Silva (BRICEÑO-RUIZ, 2020, p.22).

Não por acaso, o otimismo econômico e político na região, atrelado a políticas migratórias mais brandas impulsionaram a América Latina a figurar, de forma significativa, nas rotas migratórias internacionais, bem como presenciar um considerável crescimento e reconfiguração da já estabelecida migração intrarregional. O crescimento econômico regional, aliado ao aumento do emprego na regiáo, bem como de políticas sociais de combate à pobreza, foram importantes atrativos para intensificar a já presente migração regional e internacional na América Latina e no Caribe (GRANJA; VILLARREAL, 2017).

Por outra parte, grupos migratórios que, por conta do forte legado colonial, mantêm rotas de migraçáo para países europeus, por exemplo, tornaram-se presentes também na região. Durante a última década, registrou-se um aumento das chegadas e uma diversificação das origens nacionais dos migrantes oriundos de países africanos e asiáticos. O crescimento substancial desses grupos migratórios respondeu, em boa medida, ao processo de reforço de fronteiras produzidos no Atlântico Norte (DOMENECH; DIAS, 2020, p. 46).

Em outras palavras, as políticas migratórias restritivas nas fronteiras da União Europeia e dos Estados Unidos, sobretudo a partir década de 2000, afetaram diretamente os deslocamentos migratórios oriundos da América Latina, Caribe, África e Ásia para esses dois locais. A geografia migratória de diversos grupos, portanto, fora redirecionada para a América Latina. Como já mencionado, uma região entendida como um possível corredor para se alcançar o Atlântico Norte, dado políticas migratórias brandas, ou então, graças às oportunidades de trabalho na regiáo, a chance de buscar melhorias de vida por aqui (DIAS; JAROCHINSKI SILVA; SILVA, 2020; DOMENECH; DIAS, 2020). Logo, as dinâmicas migratórias regionais passaram a ganhar um olhar mais cuidadoso. Nesse sentido, os casos da Argentina e do Equador podem ser destacados. Enquanto na Argentina presenciamos uma "virada humanitária" e um marco da Argentina redemocratizada ao reconhecer o direito de migrar, através da Ley 25.871, em 2003 (GIUSTINIANI, 2004; MORALES, 2012); no Equador, por meio da Constituição Cidadã de 2008, Rafael Correa propôs, por um curto tempo e sob várias contradições, a circulação de cidadãos sem passaporte (ÁLVAREZ VELASCO, 2019, 2020). Em outras palavras, esses governos progressistas - 
marcados por um espírito ou discurso latino-americanista - buscaram promover, de maneiras diversas e díspares, visóes mais humanitárias e abrangentes sobre as migraçóes do que seus predecessores conservadores, em termos ideológicos, e neoliberais, em termos econômicos.

No entanto, a década de progressismo na América Latina como uma quase hegemonia política começou a sucumbir juntamente com o fim do boom das commodities impulsionado pelo crescimento econômico chinês. Com o fim desse ciclo, presenciamos o declínio econômico regional assentado, sobretudo, na exportação de proteína animal e vegetal, minério e petróleo. Além disso, havia um discurso de retomada econômica por meio da reduçáo do estado, privatizaçôes, e reformas trabalhistas drásticas. Teremos, então, a retomada de governos de direita e, no caso do Brasil, de extrema-direita e da agenda neoliberal alinhada aos interesses estadunidenses, que foram silenciados durante a fase do desenvolvimentismo. De fato, em 2015 o ciclo do progressismo na América Latina estava praticamente encerrado, marco talvez assinalado pela derrota do peronismo nas eleiçóes presidenciais pelas mãos do candidato do establishment financeiro neoliberal argentino, Mauricio Macri. Esse ressurgimento de governos conservadores na regiâo resultou em uma espécie de movimento "contra-reformista". Apresentou-se diametralmente oposto a seus antecessores e disposto a reverter as conquistas populares e de direitos, por meio de uma inegável perseguição aos representantes políticos do período progressista anterior. Como exemplo, destacamos os golpes de estados ocorridos em Honduras, em 2009, no Paraguai, em 2012, no Brasil, em 2016, e, recentemente, perpetrado contra o governo de Evo Morales na Bolívia, em 2019. Além disso, os emblemáticos e recentes casos de Lawfare enfrentados por Luiz Inácio Lula da Silva e Cristina Kirchner. Portanto, este é o contexto anterior que nos permite compreender o atual cenário político, em que a regiáo permanece em uma linha ideológica fortemente conservadora, com exceção da Argentina, México e Bolívia, onde temos a presença dos ditos governos progressistas

Não por acaso, temos vivenciado a intensificação dos processos de criminalização da migração e securitização de fronteiras em escala global na América Latina. "Na América do Sul, esses processos generalizaram-se nos últimos dez anos, como resultado do deslocamento sofrido pelas políticas baseadas na expansão e proteção dos direitos da população migrante e no ressurgimento da violência do Estado" (DOMENECH; DIAS, 2020, p. 46). Em dezembro de 2018, o Chile, por exemplo, foi o primeiro país da América Latina a retirar-se do Pacto Global para a Migraçáo. O argumento apresentado repousava no fato de que o pacto não diferenciava a imigraçáo regular da irregular e que, 
portanto, iria de encontro às políticas migratórias adotadas pelo país e, portanto, feria a sua soberania nacional. Em seguida, o presidente, Sebastián Pińera, apresentou ao Congresso um pacote de rígidas medidas restritivas à entrada de migrantes bolivianos e venezuelanos. No Brasil, logo após a posse de Jair Bolsonaro, temos decretado o fim do Ministério do Trabalho, em 01 de janeiro de 2019, e o Conselho Nacional de Imigração (CNIg) é transferido para o novo "Superministério da Justiça e Segurança Pública", chefiado pelo então ministro Sérgio Moro5. Uma semana depois, em 08 de junho de 2019, o Ministério das Relaçóes Exteriores anuncia a, também, retirada do Brasil do Pacto Global para a Migração, o qual o país tinha aderido em dezembro, no fim do governo Michel Temer. Bolsonaro publica, como de costume, em sua conta particular do Twitter uma justificativa centrada no que compreende assegurar o espírito de brasilidade no país:

Quem porventura vier para cá deverá estar sujeito às nossas leis, regras e costumes, bem como deverá cantar nosso hino e respeitar nossa cultura. Não é qualquer um que entra em nossa casa, nem será qualquer um que entrará no Brasil via pacto adotado por terceiros. (NÃO É..., 2019, grifo nosso).

Sob um argumento nacionalista retrógrado e que vai de encontro à longa tradição das políticas de relaçóes externas brasileiras, onde fronteiras deveriam ser vistas como um símbolo de cooperação e não de divergência ou disputas de interesse, Jair Bolsonaro se prende, aos elementos mais básicos e questionáveis para impor sua suposta política nacionalista à migrantes econômicos e refugiados. Cabe frisar que esse nacionalismo fortemente enviesado por uma postura xenófoba guarda também forte influência da gestão de Donald Trump (20172021), com suas políticas securitárias sobre o possível impacto que os grandes deslocamentos migratórios através da América Latina poderiam causar sobre as fronteiras estadunidenses. Nessa tônica, destacamos as inúmeras visitas de seu Secretário de Estado e ex-diretor da Agência Central de Inteligência (CIA), Mike Pompeo, na América Latina. Por exemplo, sua presença constante em casos delicados como a do Grupo de Lima. Composto por representantes de diversos Estados das Américas, esse grupo, criado em 2017, passou a representar a posição regional sobre migração e refúgio dos novos governos da nova direita. Por meio do documento conhecido como Declaração de Lima, o grupo propôs

5 O Ministério do Trabalho vem a se tornar uma secretaria especial do, também, "Superministério da Economia", chefiado por Paulo Guedes. 
"abordar a crítica situação da Venezuela e explorar formas de contribuir para a restauração da democracia naquele país através de uma saída pacífica e negociada" (BRASIL, 2020).

\section{Fronteiras, a produção da vulnerabilidade e resistência migratória}

O discurso de que migrantes senegaleses, haitianos, cubanos e venezuelanos, dentre outras nacionalidades, estariam inundando países como Brasil, Equador, Chile é bastante forte no discurso midiático. Trata-se de uma imigração incontrolada, náo racionalizada ou domesticada, gerando crises ou sérios problemas de ordem social para a sociedade de destino. Trata-se do excedente que o Estado, embasado pelas leis migratórias, deve controlar. Não à toa, ela cada vez mais se tornará principal alvo de governos avessos a políticas migratórias capazes de superar leituras economicistas e propor uma compreensão da mobilidade migratória enquanto um fenômeno político. Com auxílio de setores conservadores, desenhará um quadro assustador para a populaçáo local. Tal posição legitima o emprego de força e políticas migratórias duras enquanto elementos necessários para assegurar a segurança do território nacional e, sobretudo, para seus cidadãos. Ambiciona, dessa forma, "determinar o valor humano dos espaços de posse, dos espaços defendidos contra forças adversas, dos espaços amados" (BACHELARD, 2000, p.19). Esse é o tema do artigo que abre nosso dossiê. A partir de uma análise político-midiática, o artigo “Análise do 'normatizar' da crise venezuelana no Brasil e sua relação com a política discursiva da operação acolhida” explora o viés securitário com que o aumento do deslocamento migratório de venezuelanos, a partir de 2017, foi percebido pela sociedade brasileira. Segundo a autora, Victória Machado, a presença venezuelana em Roraima foi entendida, desde o início, como uma "crise" e/ou um "problema social", pela sociedade brasileira. Isso pode ser vislumbrado nas ações humanitárias que, segundo ela, trabalharam de forma contraditória: ora centradas em um discurso e práticas benevolentes, ora centradas no medo de uma suposta invasão e risco de ameaça à sociedade de acolhida. Machado argumenta que tal dinâmica viria a ser reforçada com a criação da Operação Acolhida, em 2018. As divulgaçóes promovidas pelo exército brasileiro e a mídia tiveram a capacidade de gerar espectadores sensibilizados frente à vulnerabilidade de venezuelanos que acabavam de atravessar a fronteira, bem como gerar uma parcela que, por sua vez, defendiam o fechamento da fronteira, com deportação e restrição aos serviços básicos de saúde. Em suma, construiu-se a imagem de militares enquanto estabilizadores e pacificadores para 
a sociedade local, em detrimento da ameaça venezuelana a uma suposta estabilidade local.

$\mathrm{Na}$ mesma tônica, focando o impacto midiático e governamental sobre a população quanto a legitimação de políticas migratórias duras, temos o segundo artigo: “¿Qué hacemos con los migrantes? Representaciones de alumnos de escuelas medias de villa lugano y discursos políticos sobre la migración limítrofe. Buenos aires 2016-2018”, de Federico Luis Abiuso, Gisele Kleidermacher e Darío Lanzetta. Por meio de uma pesquisa realizada com alunos do ensino médio em Villa Lugano, Buenos Aires, os autores analisam a percepção do público escolar em relação ao acesso de migrantes à assistência social pelo Estado. Em paralelo, exploram os discursos políticos sobre migração, que acompanharam as mudanças na legislação migratória argentina nos últimos anos, levando à sanção do DNU 70/2017 ${ }^{6}$, bem como matérias publicadas em jornais argentinos de grande circulação como o Clarín e La Nación. Por meio da análise de dados, os autores demonstram como esse discurso conservador e que atrela migração a ideia de custo e risco social invade os muros da escola e se faz presente no discurso da comunidade escolar, incluindo os estudantes.

Portanto, fronteiras externas e internas e seu modus operandi moldam a vida daquelas e daqueles que adentram as fronteiras latino-americanas ou ambicionam usar essa ampla região para alcançar, por exemplo, os Estados Unidos, embora a mobilidade humana tenha aumentado na região, graças a uma economia global ávida por força laboral; governos nacionais, como demonstrado até aqui, têm, gradualmente, reforçado o controle de suas fronteiras, bem como aumentado a restrição da livre circulação humana por entre territórios. Aqui temos, portanto, o terceiro artigo do dossiê: "Claves para entender la política migratoria mexicana en tiempos de López Obrador”, de Leticia Calderón Chelius, que nos oferece uma leitura bastante interessante. A partir do governo de López Obrador, bastante marcado por políticas internas, Chelius reflete como políticas migratórias que, por sua vez, exigem negociaçóes internacionais com os países limítrofes, têm sido trabalhadas de forma secundária e sem nenhum compromisso com a população em mobilidade envolvida. Nessa ótica, coloca-se em xeque dois importantes pontos em torno do governo mexicano. $\mathrm{O}$ primeiro refere-se às expectativas criadas em torno desse governo progressista, na medida em que seus vizinhos na América do Sul mergulhavam em governos conser-

\footnotetext{
6 Decreto de Necessidade e Urgência (DNU 70/2017), instituída pelo governo neoliberal de Mauricio Macri (20152019) e que buscou modificar a Ley Nacional de Migraciones 25.871, instituída em 2003. Fortemente criticada por setores progressistas e associações de migrantes ao longo do país, pois violava o devido processo legal, o direito à defesa e o direito à unidade familiar, a DNU 70/2017 viria a ser revogada no primeiro semestre de 2021, pelo, então, presidente em exercício, Alberto Fernández.
} 
vadores, e o México era visto, por muitos, como uma alternativa ou suspiro. $\mathrm{O}$ segundo refere-se às reflexóes que Chelius desenvolve sobre as caravanas de migrantes e como elas vão sendo recebidas, ao longo do território mexicano, por políticas migratórias mexicanas fortemente influenciada pelas ameaças de Donald Trump. Em outras palavras, como a própria autora aponta, a migração não parece fazer parte de suas políticas progressistas.

Os três artigos seguintes debatem a vulnerabilidade no tecido urbano de grandes cidades latino-americanas. O primeiro, "A 'provisoriedade ordinária' no cotidiano de imigrantes em São Paulo", de Caio Fernandes e Priscilla Pachi, explora questóes relativas à vulnerabilidade da população migrante na grande São Paulo, para além de um uma análise centrada no nível jurídico restrito às leis migratórias. Por meio de trabalho de campo realizado nos alojamentos da Missão Paz, mundialmente conhecida pelo importante trabalho de acolhimento aos migrantes, realizado pelos Scalabrianos, Fernandes e Pachi trazem o tema da provisoriedade para adensar o debate. As precárias e incertas condiçóes de trabalho oferecidas a esses migrantes, bem como a falta de representatividade política que eles têm na sociedade receptora, seriam sinais de tal provisoriedade que, por sua vez, acentuam a condiçáo de vulnerabilidade. Nessa tônica, a provisoriedade torna-se a condição existencial desses migrantes em uma das maiores cidades da América Latina. Aqui, adicionaríamos também deslocado. Deslocado não apenas territorialmente, mas, sobretudo, politicamente. Em outras palavras, o migrante passa a conviver com a ausência completa de um lar político. E, nesse caso, a condição da provisoriedade atinge seu ponto máximo.

Ao que tudo indica, atos cotidianos como morar, trabalhar, acessar pontos distantes através de transporte público tornam-se uma prática diária um tanto hostil para esses migrantes não só destituídos de cidadania, mas, também, de direitos humanos. Aqui contamos com os dois artigos seguintes - ainda na tônica da vulnerabilidade no tecido urbano - que exploram essa temática por meio de pesquisas de campo realizadas com migrantes senegaleses, respectivamente, em Buenos Aires e Porto Alegre. Em diálogo com o artigo de Federico Luis Abiuso, Gisele Kleidermacher e Darío Lanzetta, aqui veremos o discurso conservador e fortemente enviesado por um legado escravocrata ganhar as ruas dessas duas importantes capitais meridionais da América Latina. O primeiro trata-se do texto "La criminalización de senegaleses en la Ciudad de Buenos Aires, en el período 2015-2019. Un acercamiento desde la interseccionalidad”, de Jeremías Pérez Rabasa. Ele debruça-se sobre a migração senegalesa na Cidade Autônoma de Buenos Aires. Sua contribuição é compreender o processo de criminalização a que esses migrantes foram submetidos durante a gestáo liberal-conservadora 
de Mauricio Macri e a Alianza Cambiemos. Rabasa apresenta o cruzamento de diferentes discriminaçóes contra a comunidade senegalesa e como elas atuam cruelmente na construção de uma relação de alteridade centrada na criminalização do outro e, por conseguinte, na justificativa para a violência estatal. Em diálogo, também, com o texto de Caio Fernandes e Priscilla Pachi, Rabasa, argumenta que diferentes formas de discriminação se cruzam na produção da vulnerabilidade vivida por senegaleses na capital argentina.

Já o terceiro artigo, "Parece que tão escondendo alguma coisa’: discursos coloniais sobre a venda de rua senegalesa em Porto Alegre (RS)”, de Filipe Seefeldt de Césaro, centra-se no tema da vulnerabilidade vivida por vendedores ambulantes senegaleses na cidade de Porto Alegre. Em particular, explora matérias jornalísticas preconceituosas produzidas pelo jornal porto-alegrense Zero Hora e como elas atingem a população ordinária. Como o autor analisa, trata-se de um discurso que atrela a migração senegalesa a um histórico discurso racial, que remete à ordem colonial brasileira. $\mathrm{O}$ desconhecimento sobre as condiçóes de vida do outro e o egoísmo meritocrático, tão presentes na sociedade brasileira, modelam um duro discurso que afirma serem os senegaleses os grandes responsáveis por trazerem o caos ao centro de Porto Alegre. Com suas mercadorias e em constante mobilidade, supostamente se recusam a atender uma dada racionalidade local, que tem em seu discurso imaginário, nos valendo de Benedict Anderson (2006), supostas origens em uma Europa setentrional. Baseado em um referencial teórico pós-colonial, de Césaro busca compreender como termos são gerados, na grande mídia, e estão em sintonia com o que se vivencia nas ruas da capital gaúcha. Mais uma vez, temos a experiência "topofóbica" em cena. Enquanto Macarena Williamson Modesto nos demonstra o medo do espaço social ao longo do ato político da caminhada fronteiriça, Filipe Seefeldt de Césaro nos demonstra tais sentimentos vividos na cidade.

Através de uma leitura diacrónica, Maria Graciela de Ortúzar Correio, por sua vez, argumenta que a vulnerabilidade migratória não é sincrônica. Em seu artigo "¿Migrantes "vulnerables”? políticas de migración y derecho a la salud en Argentina”, a autora demonstra como a vulnerabilidade é de uma intensa luta travada entre grupos migrantes, Estados e organizaçóes sociais e internacionais. Uma constante disputa política onde minorias sociais não podem ceder sua existência política. Nessa perspectiva, Ortúzar Correio parte dos riscos impostos pelo Decreto de Necessidade e Urgência (DNU 70/2017) na Argentina, durante a gestão de Mauricio Macri, a partir de 2017, ao retirar o direito ao acesso à saúde enquanto direito humano básico, garantido pela Ley 25.871, de 2003. Ao longo do texto, ela demonstra como a DNU 70/2017, sob um discurso de 
securitização, buscou restringir o serviço de saúde público argentino apenas àqueles migrantes empregados.

Embora as fronteiras sejam aprimoradas diariamente e o aparato jurídico, também, reforçado para detectar e remover migrantes das bordas e territórios internos sob o conservador discurso da segurança nacional, esse dossiê demonstra que migrantes ainda são atores sociais com poder. A vulnerabilidade, nesse sentido, torna-se um elemento a ser combatido. Esse é, aliás, um ponto explorado nos artigos acima. Todavia, ganha maior realce nos três artigos que apresentaremos a seguir. E, nesse sentido, entramos no artigo de Macarena Williamson Modesto, que retoma o tema das caravanas migrantes ao longo da América Central.

Logo no início de seu texto, "Sentir en movimiento: emociones de mujeres salvadoreñas sobre la vida cotidiana y el tránsito migratorio por Tapachula, estado de Chiapas, México", ela nos informa que à luz da teoria crítica feminista, explora como mulheres salvadorenhas negociam suas mobilidades migratórias através da cidade fronteiriça mexicana de Tapachula. Sua pesquisa é centrada particularmente em duas mulheres: uma cisheterossexual e uma mulher transgênero. Sentimentos como medo, raiva e desejo estão envolvidos na construção de suas respectivas mobilidades fronteiriças. Tratam-se de sentimentos topofóbicos, frutos de desigualdades como, por exemplo, a de gênero que transformam o espaço social a ser percorrido (BACHELARD, 2000; TUAN, 2013). Todavia, eles não são absolutos, pois migrantes têm a capacidade de agenciamento para enfrentar seu vulnerável trânsito migratório. Em suma, Williamson Modesto, argumenta que a vulnerabilidade migratória não equivale a um movimento unilateral de poder. Porém, o constante processo de reelaboração das subjetividades vividas por suas entrevistas, nesse constante estar-em-trânsito, também, permitem o enfrentamento.

Em diálogo com o texto de Macarena Williamson Modesto, entramos no artigo "'Cada persona tiene derecho a estar donde su corazón está: Maternar una familia transnacional”, de Amarela Varela Huerta e Ana Laura López Correio. As autoras aprofundam o debate acerca da resistência à vulnerabilidade migratória produzida pelo estado, no caso, estadunidense e mexicano, por meio da capacidade de resiliência apresentada por migrantes mulheres. Nesse sentido, através da trajetória de vida de uma das próprias autoras, a ativista política Ana Laura López Correio, acompanhamos a batalha vivida por mulheres migrantes entre as fronteiras da América Latina com os Estados Unidos. Em particular, elas, minuciosamente, demonstram como as dificuldades e habilidades na construção de uma família transnacional geram importante formação política e autoconsciência da condição migratória, bem como as contradições presentes nas políticas migra- 
tórias impostas em torno do visto, por parte do governo dos Estados Unidos. Longe de romantizar, a vulnerabilidade torna-se, portanto, um ponto de ruptura, questionamento e luta migrante vivida na América Latina.

São, portanto, dois textos que nos convidam a refletir a vulnerabilidade no ato da mobilidade migratória. Sob essa perspectiva, o ato de estar-em-trânsito, em si, apontado em dois deles, não pode ser ignorado ou ocultado em estudos que buscam ampliar a compreensão em torno da vulnerabilidade migratória. Caminhar ou trilhar, a mobilidade migratória se mostra como um processo de negociação com o espaço social por onde ela se realiza. Tal posicionamento crítico possibilita ao pesquisador compreender a migração, em si, não como fluxo, mas como uma prática social e política, do próprio ator migrante. Portanto, ela é carregada de experiências vividas, negociadas e produzidas através do espaço social (LEFEBVRE, 1991; GERBAUDO SUÁREZ, 2018; DIAS, 2019).

Similar posição pode ser presenciada no ato de ocupar politicamente os espaços por onde a vida em condição migratória se faz, como o texto de Alfonso Hinojosa Gordonava ressalta. Em seu artigo “Jóvenes migrantes y política: los nuevos rostros de la bolivianeidad en Argentina”, o autor explora formas de resistências produzidas por jovens migrantes bolivianos e, sobretudo, migrantes mulheres, que trabalham e vivem em Buenos Aires, contra políticas de securitização. Em particular, contra o decreto DNU 70/2017 já mencionado anteriormente. Hinojosa Gordonava busca sair de um arriscado discurso de vitimização e demonstrar o papel central das lutas migrantes, organizaçóes e mobilizaçóes coletivas para conter a precarização e vulnerabilidade produzidas pelo estado argentino. Em outras palavras, temos a construção do que o autor cuidadosamente define como o sujeto político migrante. Sua análise é elaborada por meio de pesquisa de campo realizada com coletivos centrados, por exemplo, na atividade laboral ou no combate ao feminicídio e infanticídio.

Por outro lado, é inevitável mencionar as mudanças drásticas que ocorreram desde o final de 2019 com o início da pandemia global causada pela COVID-19. Com efeito, perante os gravíssimos problemas sociais e económicos que a pandemia tem causado de forma generalizada, é preciso dizer que, pela primeira vez na história da humanidade, assistimos a uma imobilização total e global das pessoas em consequência das medidas de saúde adotadas globalmente. É claro que, no que diz respeito ao nosso interesse temático, as migraçôes de diferentes naturezas foram gravemente afetadas, tanto por sua incapacidade de se desenvolver quanto pelo aumento das condiçóes de vulnerabilidade. Um dos principais usos sociais da pandemia tem sido o de produzir um incontrolável medo do vírus, do outro, do contágio, da doença e, em última instância, da 
morte, o que justificou o fechamento de fronteiras e a adoção de uma série de medidas para controlar a mobilidade da populaçáo no interior dos espaços nacionais. Estrangeiros encarnam a figura dos outros-alheios, dos corpos racializados que são suspeitos. Como dito na abertura, em tempos de pandemia, a suspeita se exacerba, como também o medo de que esses corpos alheios sejam vetores de contágio. Em vários países foram registradas formas de xenofobia social e estatal sofridas por certas categorias de migrantes. É o caso da Guatemala, por exemplo, onde tanto o governo quanto a sociedade viram com maus olhos a chegada dos guatemaltecos contaminados e deportados dos Estados Unidos; ou, no caso do Chile, onde autoridades governamentais recentemente, no norte do país, expulsaram, através do "Plano Colchone", 138 migrantes indocumentados; ou o argentino, onde "deportaçóes acordadas" foram instauradas para certos turistas como coreanos e europeus; ou o brasileiro, com a deportação de 200 bolivianos que buscavam acesso ao Sistema Único de Saúde (SUS) na fronteira de Corumbá.

Destacamos, assim, o artigo que fecha o nosso dossiê: "As interfaces da vulnerabilidade social de imigrantes e refugiados frente a covid-19: cenário MatoGrossense”, de Kelly Pellizari e Henrique Roriz Aarestrup Alves Correio. Nele, temos um frutífero diálogo com o texto de Maria Graciela de Ortúzar Correio ao atrelar vulnerabilidade, acesso a saúde e migração. Todavia, oferece-nos uma abordagem distinta: explora como as políticas sanitárias de combate a covid-19, negligenciada a trabalhadores migrantes e sob condição de refúgio. E o impacto da vulnerabilidade no dia a dia por meio das esferas do trabalho, jurídica, habitacional. Por meio de uma perspectiva qualitativa, a pesquisa entrevistou cerca de 30 imigrantes residentes no estado do Mato Grosso para compreender quais os principais desafios enfrentam frente o espalhamento da pandemia e, sobretudo, a falta de políticas sociais capazes de auxiliá-los na lida contra a COVID-19. Cabe destacar que o texto traz ainda outro ponto rico: ele nos permite compreender esse tema longe de grandes centros urbanos e político decisórios brasileiros como, costumeiramente, ocorre no circuito acadêmico. Pellizari e Alves Correio exploram o impacto no interior brasileiro, refém do agronegócio e responsável pela produção de proteína animal e vegetal em larga escala e para exportação.

Trazemos, portanto, para a Cadernos de Campo o diálogo entre migraçôes e vulnerabilidade por meio de um profícuo diálogo entre os campos das ciências sociais. Os artigos aqui apresentados, ademais, exploram a migração com informaçóes provindas de distintas fontes de pesquisa. Trabalho de campo 
multissituado, etnografia, usos de entrevistas, documentação e imagens, por exemplo, são alguns dos métodos utilizados nos textos que compóem o dossiê.

Nesta compilação de trabalhos coletados, pretende-se explorar como sujeitos migrantes, diariamente, negociam suas existências em diversos contextos rurais e urbanos em países latino-americanos. Contextos que, agora, os tornam duplamente vulneráveis, já que, por um lado, os governos conservadores da região impóem políticas fortes contra a migração, e, por outro, o contexto de uma pandemia permite que justifiquem suas açôes desumanas, paradoxalmente e a pretexto de usar razóes de saúde com medidas ainda mais arbitrárias, mais restritivas e mais duras como a expulsão massiva de migrantes, como já referido.

Por fim, gostaríamos de agradecer individualmente aos autores e às autoras que submeteram seus textos para esse dossiê. Deixamos, também, nossos agradecimentos à equipe editorial da Cadernos de Campo, por encampar essa proposta que fomenta o debate crítico sobre as políticas e práticas de controle de migração e fronteira da América Latina e Caribe. Esse dossiê começou a ser formulado no início de 2020. Portanto, ele pegou o processo de transição entre editores-chefes do periódico. Logo, gostaríamos de agradecer ao ex editor-chefe Isaias Albertin de Moraes, que recebeu com bons olhos e muito cuidado a proposta. Gostaríamos, também, de agradecer aos novos editores-chefes, na figura de Aline Cristina Ferreira, que, sempre muito cuidadosa, nos auxiliou com toda a condução do processo. Por fim, mas não menos importante, agradecemos muito à Domila Pazzini pela concessão da imagem $O$ pôr do sol em Playas de Tijuana, tirada na fronteira localizada no extremo norte do México e que ilustra a capa da edição e faz referência ao dossiê. Essa é uma das inúmeras fotos tiradas durante seu trabalho de campo no extremo norte do México e que revelam o fatídico muro que avança e separa vidas entre Tijuana e San Diego, nos Estados Unidos. Desejamos a todas e todos uma boa leitura e reflexóes!

\section{REFERÊNCIAS}

ÁLVAREZ VELASCO, S. From Ecuador to elsewhere: the (re)configuration of a transit country. Migration and Society, Oxford, v.3, n.1, p. 34-49, 2020.

ÁLVAREZ VELASCO, S. Ecuador-México-EE.UU.: la producción de una zona de tránsito entre políticas de control y la autonomía de la migración. In: CORDERO, B.; MEZZADRA, S.; VARELA HUERTA, A. (org.). América Latina en movimiento: migraciones, límites a la movilidad y sus desbordamientos. Madrid: Traficantes de Sueños; Tinta Limón; UACM, 2019. p. 63-97. 
ANDERSON, B. Imagined Communities: Reflections on the Origin and Spread of Nationalism. New York: Verso Book, 2006.

BACHELARD, G. A poética do espaço. São Paulo: Martins Fontes, 2000.

BENEDETTI, A. Espacios fronterizos del sur sudamericano: propuesta de un modelo conceptual para su estudio. Estudios Fronterizos, Mexicali, v.15, n.29, p. 11-47, 2014 .

BRASIL. Ministério das Relaçóes Exteriores. Declaração do Grupo de Lima. Brasília, 05 jan. 2020. Disponível em: https://www.gov.br/mre/pt-br/canais_atendimento/ imprensa/notas-a-imprensa/2020/declaracao-do-grupo-de-lima-6. Acesso em: 22 jun. 2021.

BRICEÑO-RUIZ, J. Da crise da pós-hegemonia ao impacto da COVID-19: o impasse do regionalismo latino-americano. Cadernos de Campo, Araraquara, n. 29, p. 21-39, 2020.

BRODSKY, J. Sobre o exílio. Belo Horizonte: Âyiné, 2018.

DIAS, G. Mobilidade migratória: uma leitura crítica para além de metáforas hidráulicas. REMHU: Revista Interdisciplinar da Mobilidade Humana, Brasília, v. 27, p. 61-78, 2019.

DIAS, G.; JAROCHINSKI SILVA, J. C.; SILVA, S. Travelers of the Caribbean: positioning Brasília in Haitian migration routes through Latin America. VIBRANT: Virtual Brazilian Anthropology, Brasília, v. 17, p. 1-19, 2020.

DOMENECH, E.; DIAS, G. Regimes de fronteira e -ilegalidade- migrante na América Latina e no Caribe. Sociologias, Porto Alegre, v. 22, n.3, p. 40-73, 2020.

FÉLIZ, M.; PINASSI, M. (org.). La farsa neodesarrollista y las alternativas em América Latina y el Caribe. Buenos Aires: Herramienta Ediciones, 2017.

GERBAUDO SUÁREZ, D. Juventudes latinoamericanas en Buenos Aires: luchas migrantes y configuraciones transnacionales de lo local. Argumentos: Revista do Departamento de Ciências Sociais da Unimontes, Montes Claros, v. 15, n. 1, p.213235, 2018.

GIUSTINIANI, R. Migración: un derecho humano. Buenos Aires: Prometeo, 2004. GRANJA, L.; VILLARREAL, M. Mercosur migrante: enfoques y evolución del tratamiento de la movilidad humana en el Mercosur. Terceiro Milênio: Revista Crítica de Sociologia e Política, Campos dos Goytacazes, v. 8, p. 49-78, 2017.

KATZ, C. Neoliberalismo, neodesarrolismo, socialismo. Buenos Aires: Batalla de Ideas, 2016. 
LEFEBVRE, H. The production of space. Cornwall: T.J. Press, 1991.

MILLS, W. The sociological imagination. New York: Oxford University Press, 1959.

MORALES, D. Derechos humanos de los migrantes en Argentina: apuntes sobre nuevas perspectivas jurisprudenciales. Revista Derecho Público, Providencia, año I, n.2, p.345-358, 2012.

NÁO É qualquer um que entra em nossa casa, diz Bolsonaro ao justificar saída de pacto migratório. Congresso em Foco, Brasília, 9 jan. 2019. Disponível em: https:// congressoemfoco.uol.com.br/governo/nao-e-qualquer-um-que-entra-em-nossa-casadiz-bolsonaro-ao-justificar-saida-de-pacto-migratorio/. Acesso em: 22 jun. 2021.

PINASSI, M. Neodesarrollismo: uma parábola de ricos para pobres. In: FÉLIZ, M.; PINASSI, M. (org.). La farsa neodesarrollista y las alternativas em América Latina y el Caribe. Buenos Aires: Herramienta Ediciones, 2017. p.153-171.

RIVERO SIERRA, F. Pensar el espacio, pensar los sujetos migrantes: para una teoría de la apropiación subjetiva del espacio. Argumentos: Revista do Departamento de Ciências Sociais da Unimontes, Montes Claros, v. 15, n. 1, p. 37-67, 2018.

RODRIGUES, L. Itinerário da construção das abordagens de desenvolvimento. Argumentos: Revista do Departamento de Ciências Sociais da Unimontes, Montes Claros, v. 3, n. 1, p. 37-67, 2009.

SAYAD, A. La doble ausencia: De las ilusiones del emigrado a los padecimentos del inmigrado. Barcelona: Anthropos Editorial, 2010.

SAYAD, A. A imigraçáo ou os paradoxos da alteridade. São Paulo: EDUSP, 1998.

SAYAD, A. Du message oral au message sur cassette, la communication avec l'absent. Actes de la recherche en sciences sociales, Paris, v. 59, p.61-72, 1985.

TUAN, Y-F. Landscapes of fear. Minessota: University of Minnesota Press, 2013.

ZIBECHI, R.; MACHADO, D. Os limites do progressismo: sobre a impossibilidade de mudar o mundo de cima para baixo. Rio de Janeiro: Consequência, 2017. 